\title{
Meslek Lisesi Öğrencilerinin İş Sağlığı ve Güvenliği Hakkındaki Tutumları
}

\author{
The Attitudes of Vocational High School Students on Occupational Health and Safety \\ Yunus ÖZTÜRK ${ }^{1}$ \\ ${ }^{1}$ Marmara Üniversitesi Fen Bilimleri Enstitüsü İ̧s Güvenliği Ana Bilim Dall, 34772, İstanbul, Türkiye
}

\begin{abstract}
Öz
Genç işçilerin kaza geçirme oranlarının diğer yaş guruplarındaki işçilere göre daha çok olduğu bilinmektedir. Bu yüzden ileriki y1llarda birer genç işçi olarak çalışma hayatına katılacak meslek lisesi öğrencilerine iş sağllğı ve güvenliği (İSG) eğitimi vermek büyük önem arz etmektedir. Yapılan bu çalışmada Fethiye Mustafa Kemal Mesleki ve Teknik Anadolu Lisesi'nde okuyan 10. ve 11. sınıf öğrencilerinin iş sağlığı ve güvenliği hakkında genel bilgi düzeyleri ölçülmeye çalışılmıştır. Bunun için anket çalışması yapılmış ve sonuçları incelenerek değerlendirilmiştir.
\end{abstract}

Daha önce yayımlanmış bir çalışmadan yararlanılarak hazırlanan 15 sorudan oluşan bir anket, meslek lisesindeki 10 . ve 11 . sınıflardaki 216 öğrenciye uygulanmıştır. Anketin istatiksel güvenirliği için belirli sayıdaki öğrenci grubuna değişik zamanlarda iki kez uygulanmış ve çıkan sonuçların birbirine $\% 97$ oranına yakın olduğu görülmüştür ( Test- tekrar test yöntemi). Bu çalışmanın sonucunda; öğrencilerin bazı eksiklikleri olmakla birlikte, genel İSG kurallarını öğrendikleri ve çalışırken bu kurallara uydukları görülmüştür.

Anahtar kelimeler: Meslek liselerinde İSG, İSG eğitimi, KKD, İş kazası

\begin{abstract}
It is known that the rate of accident among young workers is higher than that of workers in other age groups. Therefore, it is very important to provide occupational health and safety(OHS) education to vocational high school students who will participate in working life as young workers in the following years. In this study, it was aimed to measure the general knowledge levels of occupational health and safety of 10th and 11th grade students in Fethiye Mustafa Kemal Vocational and Technical Anatolian High School. For this purpose, a survey was conducted and the results were examined and evaluated.
\end{abstract}

A questionnaire consisting of 15 questions prepared by using a previously published study was applied to 216 students in Grades 10 and 11 in vocational high school. For the statistical reliability of the questionnaire, it was applied twice to a certain number of students at different times and the results were close to 97\% (Test-retest method). As a result of this study; although the students have some deficiencies, it is seen that they have learned the general OHS rules and obeyed these rules while working.

Keywords: Occupational High Schools, OHS, OHS Education, Work Accident

\section{I.GIRIŞ}

Mustafa Kemal Mesleki ve Teknik Anadolu Lisesi 1981 yılından buyana eğitim ve öğretime devam eden Fethiye'nin köklü liselerinden birisidir. Lise bünyesinde Tesisat teknoloji ve iklimlendirme, Elektrik ve Elektronik, İnşaat, Harita ve Tapu Kadastro, Gemi Yapımı, Bilişı̇m ve Mobilya Dekorasyon alanları bulunmaktadır. Yaklaşık 1000 öğrencisi bulunan lise her yıl 200-250 öğrenciyi mezun etmektedir. Bu da her yıl bu sayılara yakın genç işçinin çalışma hayatına katıldı̆̆ı anlamına gelmektedir. Çalışanlar arasında genç işçilerin kaza geçirme oranlarının yüksek olduğu[1] göz önünde bulundurulduğunda lise öğrencilerinin İSG eğitimlerinin önemi ortaya çıkmaktadır.

Önceki yıllarda İSG konuları Milli Eğitim Bakanlığına bağlı meslek liselerinde ayrı bir ders olarak okutulurken, daha sonraki yıllarda bu ders kaldırılmış ve İSG eğitimlerinde süreklilik sağlanamamıştır. Günümüzde ise İSG konuları 9. Sınıf mesleki gelişim dersinin bir ünitesi olarak işlenmektedir. Bununla birlikte 12. Sınıftaki işletmelerde beceri eğitimi dersine hazırlık amacıyla; 11. sınıf öğrencilerine 8 saatlik İSG eğitimi verilmektedir. 
$\mathrm{Bu}$ eğitimler okuldaki İSG sertifikasına sahip öğretmenler tarafindan düzenlenmektedir. Ayrıca düzenlenen eğitimlerin içerikleri; çalışanların İSG eğitimlerinin usul ve esasları hakkındaki yönetmelikte belirtilen konulara göre hazırlanmaktadır[2].

6331 sayılı ISSG kanunu yürürlüğe girdikten sonra, öğrencilerin staj ve işletmelerde beceri eğitimi dersleri için sözleşme imzalayacakları firmaların ortak sağlık ve güvenlik birimleriyle İSG sözleşmesi yapıp yapmadıkları önem kazanmıştır. Okul yönetimi; özellikle kendisinden başka çalışanı bulunmayan işverenlerden, ortak sağlık güvenlik birimleriyle stajyer öğrenciler için özel İSG sözleşmesi yapmalarını istenmektedir. $\mathrm{Bu}$ sözleşmeyi yapmak istemeyen işyerlerine öğrenciler verilmemektedir.

Meslek liselerinde iş kazaları yoğunlukla öğrencilerin atölye çalışmaları esnasında meydana gelmektedir. Bu kazaların önüne geçilmesinde öğrenciler için ISG eğitimlerinin büyük önemi vardır. Özellikle Tesisat Teknolojisi ve iklimlendirme, Elektrik, Gemi yapımı, İnşaat ve Mobilya Dekorasyon alanlarında kullanılan makinalar ve el aletleri; öğrenciler ve öğretmenlerin sağlığı için büyük riskler barındırmaktadır. İSG eğitimleri; öğrencilerin bu makine ve aletlerden kaynaklanan tehlike ve risklerin farkına varmaları ve bu risklerden kaçınmaları için verilmektedir. Yine bu eğitimlerle öğrencilerin güvenlik kurallarına uymaları ve gereksiz risklerden kaçınarak güvenli çalışmayı davranış haline getirmeleri amaçlanmaktadır.

Ülkemizin iş kazaları ve işçi ölümlerinde Avrupa Birliği üyeleri arasında maalesef birinci sırada olmas1[3], ülke sanayisine kalifiye eleman yetiştirme amacinda olan meslek liselerinde verilen ISG eğitimlerinin önemini ortaya koymaktadır.

\section{YÖNTEM}

$\mathrm{Bu}$ çalışmanın amacı Mustafa Kemal Mesleki ve Teknik Anadolu Lisesi'nde öğrencilerin İSG kuralları hakkındaki tutum ve davranışlarını belirlemektir.

\subsection{Araştırma Modeli}

$\mathrm{Bu}$ çalışma, nicel araştırma yöntemlerinden betimsel tarama modeli kullanılarak gerçekleştirilmiştir. Tarama modeli, geçmişte ya da halen var olan bir durumu var olduğu şekliyle betimlemeyi amaçlayan araştırma yaklaşımıdır. Araştırmaya konu olan olay, birey ya da nesne, müdahale edilmeksizin kendi koşulları içinde ve olduğu gibi tanımlanmaya çalışılır. $\mathrm{Bu}$ çalışmadaki anket soruları daha önce yayınlanmış bir makaleden yararlanılarak hazırlanmıştır[4].

\section{2.Çalışma Gurubu}

Araştırmanın evrenini Mustafa Kemal Mesleki ve Teknik Anadolu Lisesi'nde okuyan 10. ve 11. Sinıf öğrencileri oluşturmaktadır. Örnekleme bu sınıflardaki 216 öğrenciye uygulanarak yapılmıştır.

\subsection{Veri Toplama Araci}

Mustafa Kemal Mesleki ve Teknik Anadolu Lisesi'nde İSG eğitiminin yeterliliğini belirlemek amacıyla lise öğrencilerine anket çalışması yapılmış ve öğrencilerin ISG hakkında bilgilerinin ne olduğu belirlenmiştir. Kullanılan anket 15 sorudan oluşmaktadır ve beşli Linkert[5] ölçeğine göre hazırlanmıştır. Anket sonuçlarının istatiksel analizleri yapılmıştır.

\subsection{Verilerin Çözümlenmesi}

Her soru için alınan sonuçlar grafikler halinde verilmiştir. Elde edilen veriler betimsel analiz yöntemiyle değerlendirilmiştir.

$\mathrm{Bu}$ tip araştırmalar ile olgular hakkında sistemli ve düzenli bilgilere sahip olunur. Betimleyici bir araştırmada herhangi bir ilişkinin varlığı veya yoluğu araştırılır. Örneklemden hareketle evren hakkında geniş bir bilgi sahibi olunur. Yeni hipotezlerin formüle edilmesi kolaylaşır. Betimleyici araştırmalar bize o olgunun niçin öyle olduğunu, o ilişkinin niçin öyle kurulduğunu açıklamazlar. Onun yerine olgularda neyin olduğunu, nelerin neler ile birlikte olduğunu bildirirler. Betimleyici araştırmaların sonuçları, yüzde tabloları, grafikler ile gösterilir ve değişkenler arasında ilişkinin varlığı veya yokluğu saptanır[6].

\section{BULGULAR}

1. 6331 sayılı İş Sağlığı ve Güvenliği kanunu hakkında bilginiz var $\mathrm{m}$ ?

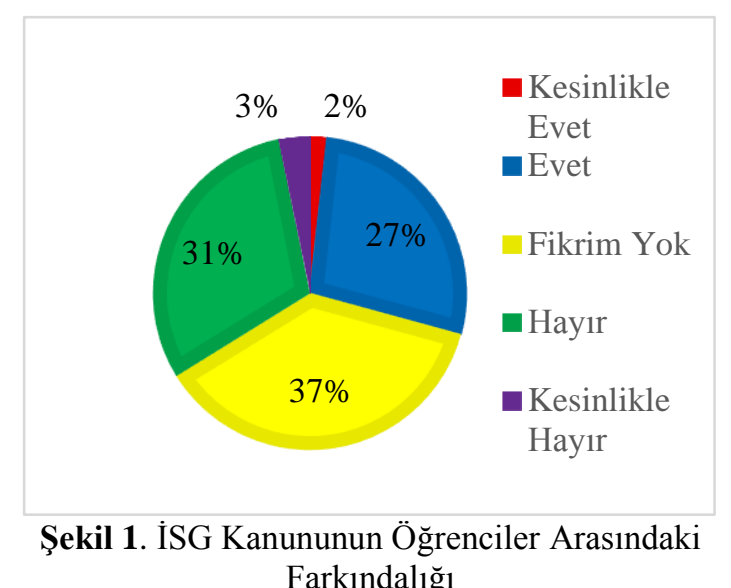

Şekil 1'deki bulgulara göre 6331 sayılı İş Sağlığı ve Güvenliği Kanunu hakkında bilgisi olan öğrenci sayısı çok azdır. Oran \%29 dur.

2. İş sağlığı ve güvenliğinin iş hayatınızı etkilediğini düşünüyor musunuz? 


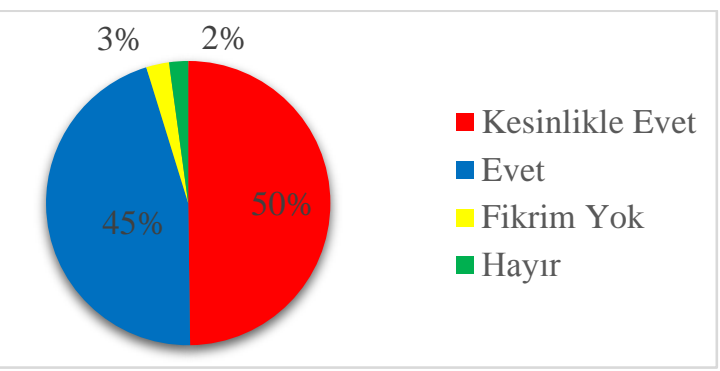

Şekil 2. Öğrenciler Açısından İSG’nin İş Hayatındaki Önemi

Şekil 2'deki bulgular öğrencilerin \%95'inin iş sağllğg ve güvenliğinin çalışma hayatını etkilediğini düşünmektedir.

3. Lise eğitiminiz boyunca işçi sağlığ 1 ve güvenliği hakkında size bilgi verildi mi?

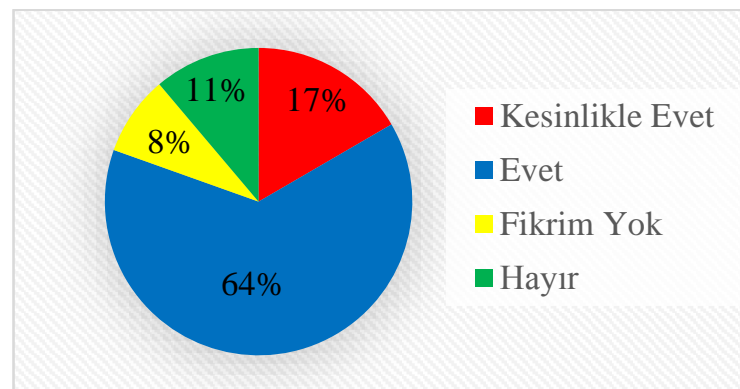

Şekil 3. Öğrencilere Lise Eğitimleri Boyunca İSG Hakkında Bilgi Verilme Durumu

Şekil 3'teki bulgular öğrencilerin \%81'nin bilgilendirildiğini göstermektedir.

4. Atölyelerde buluna İSG uyarı levhalarını çalışırken dikkate alıyor musunuz?

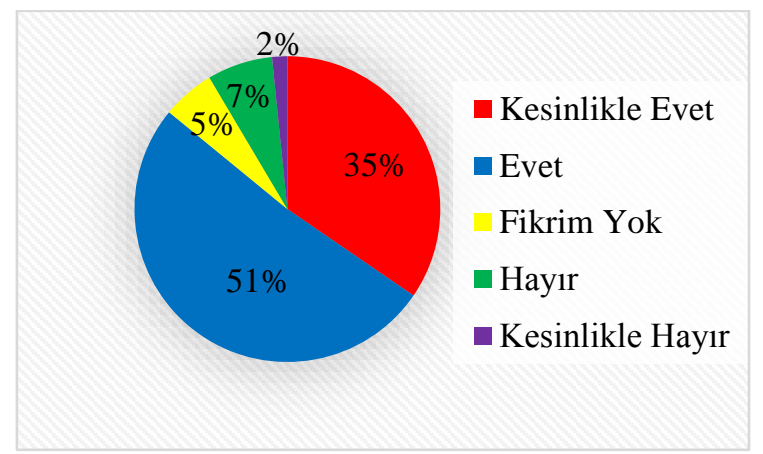

Şekil 4. Atölyelerdeki İSG Uyarı Levhalarına Öğrencilerin Verdiği Önem

Şekil 4'teki bulgular öğrencilerin \%86'sının İSG uyarı levhalarını dikkate aldıklarını göstermektedir.

5. Atölye Öğretmenleriniz ders işlerken iş sağlığı ve güvenliği kurallarına uymanızla ilgili sizi uyarıyorlar $\mathrm{m} 1$ ?

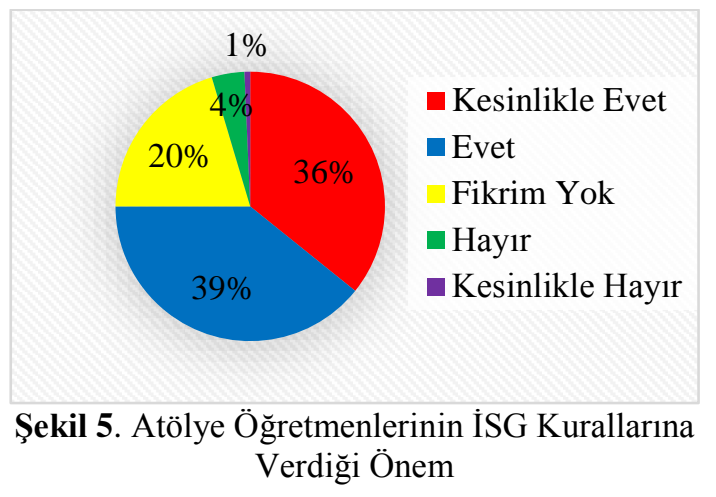

Şekil 5'teki bulgular öğretmenlerin İSG konularıyla ile ilgili hassas olduklarını ve öğrencileri derslerini işlerken güvenli çalışmaları konusunda sürekli uyardıklarını göstermektedir. Uyarı alan öğrencilerin oran1 $\% 75$ tir.

6. Öğrenci olarak atölyenizde iş güvenliği kurallarına gereken hassasiyeti gösteriyor musunuz?

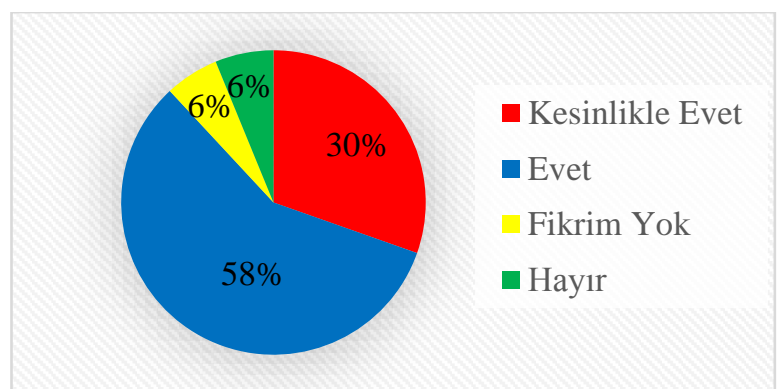

Şekil 6. Öğrencilerin Atölyelerde Çalışırken ISSG Kurallarına Verdiği Önem

Şekil 6'ya göre öğrencilerin \%88 i İSG kurallarına uyduğu görülmektedir. Ayrıca olumsuz cevap verenlerin sayıs1 \%12 iken ankette kesinlikle hayır seçeneği hiç tercih edilmemiştir.

7. Öğretmenleriniz Meslek derslerinde İş sağlığ 1 ve güvenliği konuları üzerinde duruyorlar mı?

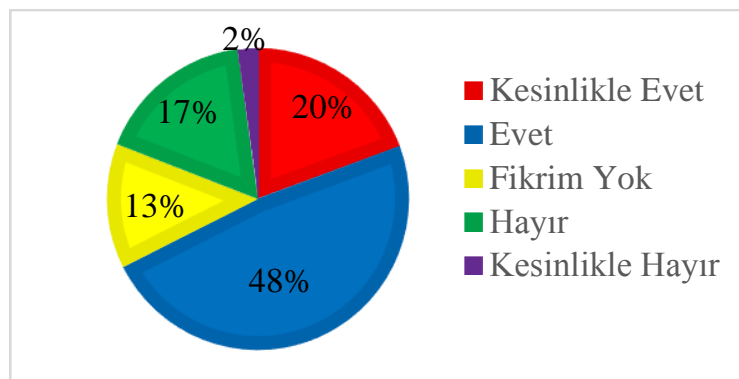

Şekil 7. Meslek Derslerinde İSG Konularının Öğretmenler Tarafından İşlenişi

Şekil 7'ye göre öğrencilerin \%68'i derslerinde ISG konularının öğretildiğini söylemektedir. \% 32'lik kısma ulaşmak içinde İSG eğitimlerine devam edilmesi gerekmektedir. 
8. Atölye derslerine giren öğretmenlerinin iş sağlığı ve güvenliği konusunda yeterli bilgiye sahip olduğunu düşünüyor musunuz?

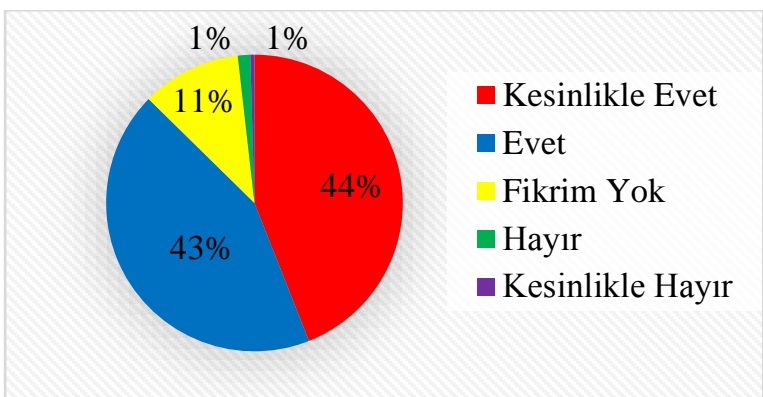

Şekil 8. Öğrenciler Açısından İSG Konuları Hakkındaki Öğretmen Yeterlilikleri

Şekil 8'e göre öğrencilerin \%87'si atölye öğretmenlerinin İSG bilgilerinin yeterli olduğunu düşünmektedir.

9. Okulunuzda İş sağlığı ve güvenliği ile ilgili ayrı bir ders olmasını ister misiniz?

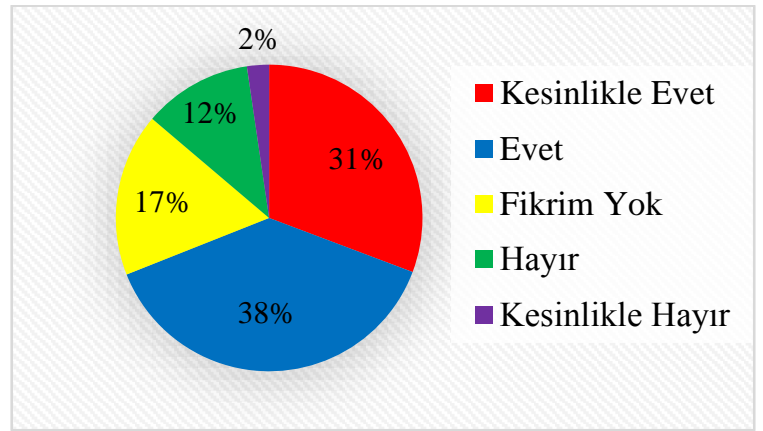

Şekil 9. İSG Konularının Ayrı Bir Ders Olarak İşlenmesi

Şekil 9'daki bulgulara göre öğrencilerin \%69'u iş sağlığı ve güvenliğinin ayrı bir ders olarak işlenmesini istemektedir.

10. Atölyelerde cihazların kullanımı ve çalışma prensibini anlatan yazılı uyarı levhalar var mıdır?

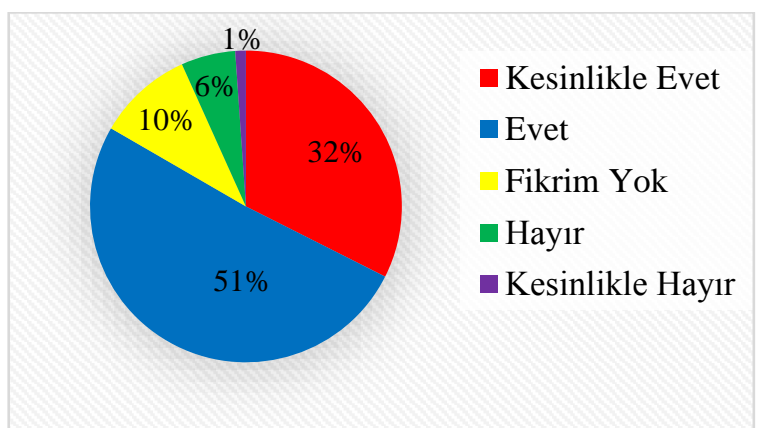

Şekil 10. Atölyelerde Kullanılan Makinaların Çalışma Prensibinin Levhalarla Gösterilmesi
Şekil 10'daki bulgular okulun atölyelerinde makine ve cihazların kullanma talimatları ve çalışma prensiplerinin yazılı olduğu levhaların üzerlerine asılı olduğunu göstermektedir.

11. Atölyelerdeki çalışmalarda kişisel koruyucu ve donanımları (KKD) kullanıyor musunuz?

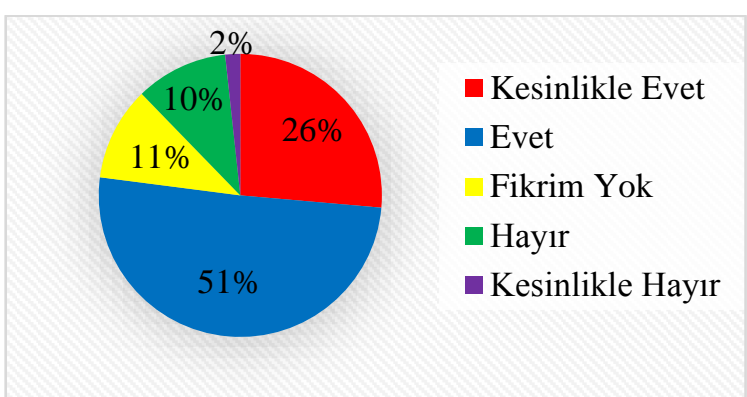

Şekil 11. Öğrencilerin Atölyelerde Çalışırken KKD Kullanım Durumu

Şekil 11'deki bulgular öğrencilerin \%77'sinin atölye derslerinde KKD kullandıklarını göstermektedir. \% 23 ü ise kullanmadığını söylemektedir. Bu öğrencilere dikkat edilip atölyede KKD kullanmaları sağlanmalıdır.

12. Okuduğunuz alanda hangi iş kazaları meydana gelir biliyor musunuz?

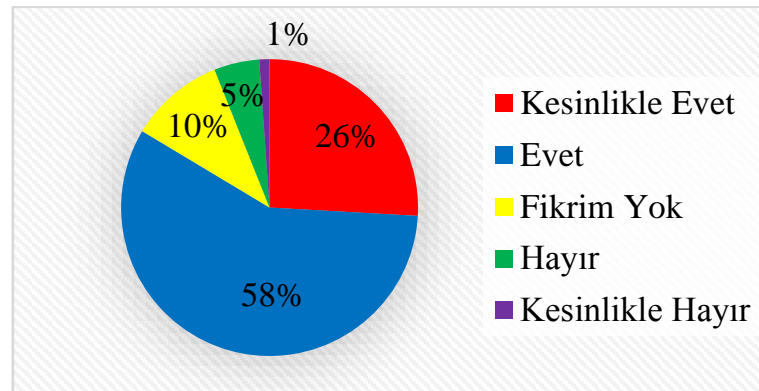

Şekil 12. Öğrencilerin Eğitim Aldıkları Alanlarla İlgili Meydana Gelen İş

Kazaları Hakkındaki Farkındalıkları

Şekil 12'deki bulgular öğrencilerin büyük bir oranının \%84'ünün mesleklerinde yaşanan kazaları bildiğini göstermektedir.

13. Okuduğunuz alanla ilgili meslek hastalıkların neler olduğunu biliyor musunuz? 


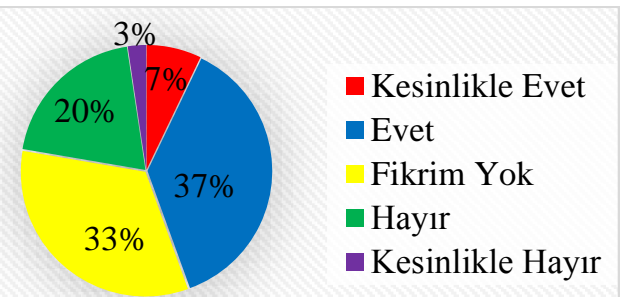

Şekil 13. Öğrencilerin Eğitim Aldıkları Alanlarla İlgili Meydana Gelen Meslek Hastalıkları Hakkındaki Farkındalıkları

Şekil 13’teki bulgular öğrencilerin $\% 56$ sının meslekleriyle ilgili meslek hastalıklarını bilmediklerini göstermektedir.

14. Mesleğiniz icabı kullanacağınız cihazlarla ilgili tehlikeler ve riskler hakkında bilgilendiriliyor musunuz?

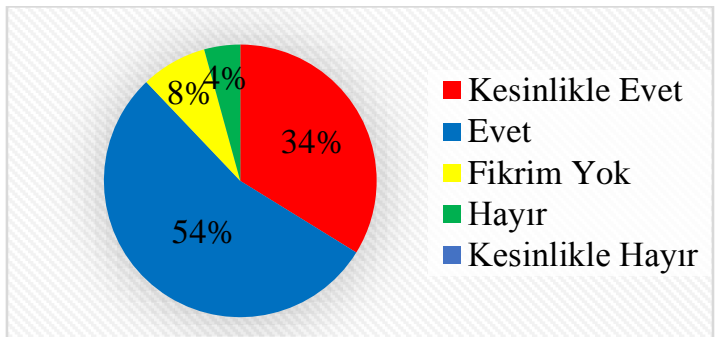

Şekil 14. Öğrencilerin Meslekleri İcabı Kullanacakları Cihazlardan Kaynaklanan Tehlike ve Riskler Hakkında Kendilerine Yapılan Bilgilendirme
Şekil 14'e göre öğrencilerin \%88 i meslekleriyle ilgili cihazları tanıdıkları ve bu cihazlardan kaynaklanan tehlike ve riskler hakkında onlara bilgi verildiği görülmektedir.

15. Atölyelerde kullandığınız cihazların tehlikeleri hakkında bilgilendirildiniz mi?

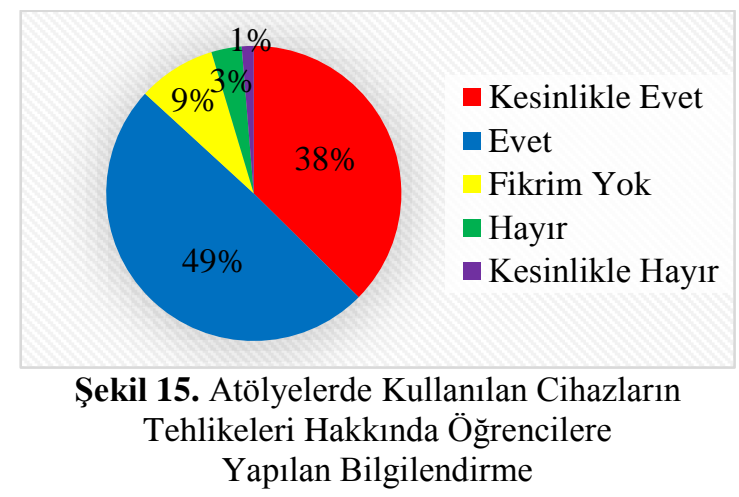

Şekil 15'e göre öğrencilerin \%87'si atölyelerde kullandıkları cihazlardan kaynaklı risklerin farkında olduğunu söylemektedir.

Ölçek için her bir maddeye verilen puan skorları 1 ile 5 arasında değişmektedir. Aralıkların eşit olduğu varsayılmış ve ağırlıklı ortalama için puan aralığı katsayısı 0.8 olarak hesaplanmıştır.

Puan Aralığı $=($ En yüksek değer - En düşük değer $) / 5$ $=(5-1) / 5=0,80$
$1-1.80$
$1.81-2.60$
: "Kesinlikle Hayır"
$2.61-3.40$
: "Hayır"
$3.41-4.20$
: "Fikrim Yok"
4.21-5.00 : : "Kesinlikle Evet"

Ağırlıklı ortalamaların değerlendirme aralığı yandaki

gibi bulunmuştur:

Maddeler

Aritmetik

Sonuç

Ortalama

1. 6331 sayılı İş Sağlığı ve Güvenliği kanunu hakkında bilginiz var 2,62963 Fikrim yok $\mathrm{m} 1$ ?

2. İş sağlığı ve güvenliğinin iş hayatını etkilediğini düşünüyor 4,282407 Kesinlikle Evet musunuz?

3. Lise eğitiminiz boyunca işçi sağlığı ve güvenliği hakkında size bilgi $3,518519 \quad$ Evet verildi mi?

4. Atölyelerde buluna İSG uyarı levhalarını çalışırken dikkate alıyor 3,75

Evet musunuz?

5. Atölye Öğretmenleriniz ders işlerken iş sağlığı ve güvenliği 4,722222 Kesinlikle Evet kurallarına uymanızla ilgili sizi uyarıyorlar mı? 
6. Öğrenci olarak atölyenizde iş güvenliği kurallarına gereken 3,893519 Evet hassasiyeti gösteriyor musunuz?

7. Öğretmenleriniz Meslek derslerinde İş sağlığı ve güvenliği konuları 3,226852 Fikrim Yok üzerinde duruyorlar mı?

8. Atölye dersleri öğretmenlerinin iş sağlığı ve güvenliği konusunda 4,101852 Evet yeterli bilgiye sahip olduğunu düşünüyor musunuz?

9. Okulunuzda İş sağlığı ve güvenliği ile ilgili ayrı bir ders olmasını $\quad 3,388889 \quad$ Fikrim Yok ister misiniz?

10. Atölyelerde cihazların kullanımı ve çalışma prensibini anlatan 3,782407 Evet yazılı uyarı levhalar var midir?

11. Atölyelerdeki çalışmalarda kişisel koruyucu (KKD) ve 3,509259 Evet donanımları kullanıyor musunuz?

12. Okuduğunuz alanda hangi iş kazaları meydana gelir biliyor 3,75463 musunuz?

13. Okuduğunuz alanla ilgili meslek hastalıkların neler olduğunu 2,925926 biliyor musunuz?

14. Mesleğiniz icabı kullanacağınız cihazlarla ilgili tehlikeler ve 3,925926 riskler hakkında bilgilendiriliyor musunuz?

Evet

15. Atölyelerde kullandığınız cihazların tehlikeleri hakkında 3,898148 Evet bilgilendirildiniz mi?

Genel ortalama:

\section{SONUCLAR}

Yapılan bu çalışmada lise öğrencilerinin İSG hakkında bilgi sahibi oldukları ve İSG kurallarına riayet ettikleri görülmüştür. Öğrencilerin kişisel koruyucu ve donanım (KKD) kullandıkları, atölyelerinde bulunan uyarı ve makina kullanım talimatlarına uydukları görülmüştür. Atölye öğretmenlerinin ISG kurallarına hâkim oldukları ortaya çıkmış ve öğrencileri atölyede

çalışırken İSG kurallarına uymaları konusunda ısrarcı oldukları anlaşılmıştır. Yine okulda bulunan atölyelerde ISG uyarı levhaları ve makine çalışma levhaları bulunmakta ve ögrenciler tarafindan dikkate alınmaktadır.

- Öğrencilerimize 6331 sayılı İSG kanununu iyi anlatılması gerekmektedir. Bunu için İş sağlığg ve güvenliği mevzuatının ayrı bir ders olarak okutulması daha etkili olacaktır.

- Öğrencilerimize meslekleriyle ilgili meslek hastalıklarının neler olduğu daha iyi anlatılmalıdır. Ayrica bu hastalıklardan korunma yolları da öğretilmelidir.

- Atölyelerde öğrenciler tarafindan kullanılacak kişisel koruyucu ve donanımların temini için okullara daha çok kaynak ayrılmalıdır.

$$
\text { 3,687346 Evet }
$$

- Teknolojideki ilerlemelerin takibi ve son teknoloji ile üretilen makinelerin okul atölyelerine kazandırılmaları öğrencilerin bu makinalardaki tehlike ve riskleri tanımalarında büyük önem arz etmektedir.

\section{KAYNAKLAR}

[1] Ceren G., Yıldırım S. (2018). Çalışanların Kişisel Özelliklerinin İş Kazası ve Meslek Hastalıklarına Etkisi Üzerine Bir İnceleme. Firat Üniversitesi IIBF Uluslararast İktisadi ve İdari Bilimler Dergisi, 2(1),53-72. Erişim adresi: https://dergipark.org.tr/tr/download/articlefile/532212

[2] Çalışanların İş Sağlığı Ve Güvenliği Eğitimlerinin Usul ve Esasları Hakkında Yönetmelik.(2013,15 Mayı), Resmi Gazete (Sayı: 28648). Erişim adresi:

https://kms.kaysis.gov.tr/Home/Goster/42267

[3] Makine Mühendisleri Odası.(2018). İş Sağlığı Ve Güvenliği Oda Raporu, (Yayın No: MMO/689). Erişim adresi: https://www.tmmob.org.tr/sites/default/files/isgr aporu2018.pdf

[4] Özgüler A., Kaya K., Kağızmanlı B., Altuğ M.,(2016), Mühendislik Fakültesi Öğrencilerinin 
İş Sağlığı ve Güvenliği Eğitimi Yeterliliği, Ĕ̌itim ve Ögretim Araştırmaları Dergisi, Haziran, 5,7586. Erişim Adresi: http://www.jret.org

[5] Turan İ., Şimşek Ü., Aslan H.,(2015), Eğitim Araştırmalarında Likert Ölçeği ve Likert-Tipi Soruların Kullanımı ve Analizi, Sakarya Üniversitesi Eğitim Fakültesi Dergisi, Aralık, (30),186-203. Erişim adresi: https://dergipark.org.tr/tr/download/articlefile/115904

[6] Aslanoğlu İ.,(2016),Sosyal Bilimlerde Metot ve Araştırma Teknikleri, Gazi Kitap Evi, (1. Bask1, Ankara, Türkiye s.10). Erişim adresi: http://www.kulamyo.cbu.edu.tr > db images , site $212>$ file > arastek 